Volume 9, No.5, September - October 2020

International Journal of Advanced Trends in Computer Science and Engineering

Available Online at http://www.warse.org/IJATCSE/static/pdf/file/ijatcse191952020.pdf

https://doi.org/10.30534/ijatcse/2020/191952020

\title{
The Use of Mobile Gamification Technology for Sustainability Learning in Saudi Higher Education
}

\author{
Mahdi M. Al Amri ${ }^{1}$, Mohammed Amin Almaiah ${ }^{1^{*}}$ \\ ${ }^{1}$ Educational Technology, King Faisal University, Al-Ahsa 31982, Saudi Arabia \\ 1*Department of Computer Networks and Communications, College of Computer \\ Sciences and Information Technology (CCSIT), King Faisal University, \\ Al-Ahsa 31982, Saudi Arabia \\ *Corresponding author: Mohammed Amin Almaiah \\ (malmaiah@kfu.edu.sa).
}

\begin{abstract}
Mobile game applications are perceived as an appropriate solution for promoting the sustainability of learning among students due to its useful and unique characteristics. Educational mobile games is the use of mobile game applications for enhancing the learning process. Recently, this topic has been getting a lot of attention from many scholars. However, the amount of research undertaken on mobile gamification is still limited. One of the main problems that hinder the success of mobile gamification is sustainability. Designers might overlook some important factors that increase the sustainability of learning due to lack of models that covers all the essential factors to achieve this goal. Therefore, this study proposes a new model that aims to enhance the learning sustainability using mobile gamification applications. This research provides empirical evidence and explains some important factors, such as enjoyment, perceived ease of use, perceived usefulness, behavioural intention to use, efficiency and effectiveness, to facilitate the effective utilization of mobile gamification applications, and thus, will contribute in increasing the sustainability of learning effectively using mobile game applications.
\end{abstract}

Key words : Mobile game applications, Gamification, Sustainability, Mobile games, Enjoyment.

\section{INTRODUCTION}

In the recent years, mobile game applications have been applied in higher education context [4]. Educational mobile game applications is the use of entertainment for conducting the learning process, which includes mobile games, simulations and gamification. Recently, mobile gamification applications have gained popularity in higher education context [1] and it is being benefited from its characteristics in the learning context [2], [3]. It is used to increase the learning motivation among students, enhance students' engagement and increase the sustainability of learning in an effectively way [4]. mobile gamification can be defined in various ways. For example, Holden and Sykes [7] defined the educational mobile gamification as an entertainment activity in which students pursue educational goals in order to acquire knowledge and develop their skills in mobile learning environments. Huizenga et al. [8] defined the educational mobile gamification is one of the digital games designed for conducting the learning process in entertainment way. This definition comes close to the idea professed by Prensky [9], whose concept of digital learning is the marriage of learning and digital entertainment. In sum, these definitions indicate the role of digital learning games (computer and mobile) as acting as an entertainment platform designed for the learning process of its students.

However, there are several ways for implementing mobile gamification in order to promote student's engagement. But, it is not always guaranteed that the implementation of mobile gamification in a successful way due to lack some important factors and techniques. Thereby, in order to success these applications, it is very important to complement mobile gamification with these factors and techniques. For example, many studies showed that including some crucial factors like enjoyment, easefulness and ease of use to mobile gamification can further enhance student's engagement [5]. In fact, the more mobile gamification application is simple, more easy to use and more entertainment, longer students will interact with these applications, they will become an expert with it, and thus, increasing the sustainability of learning through using mobile gamification applications.

Although there are several factors that promote the sustainability of learning including enjoyment, easefulness, ease of use, efficiency and effectiveness. However, applying these factors into mobile gamification has not been adequately addressed in the literature. Moreover, it is necessary to understand their effects on mobile gamification usage among students. For example, enjoyment is one of the key factors for motivating students to use mobile gamification applications since this factor helps in increasing students' engagement in learning process. However, designers might overlook some important factors 
that increase the sustainability of learning due to lack of models that covers all the essential factors to achieve this goal.

Therefore, this study proposes a new model that may increase the sustainability of learning among students by exploring the essential factors that influencing the enhancement usage of mobile gamifiction applications. The proposed model includes the following factors: enjoyment, ease of use, usefulness, behavioural intention to use, efficiency, effectiveness and utilization in the adoption of mobile gamifiction applications. The proposed model will help researchers to guide future research in the field of mobile gamification adoption in higher education. Therefore, this study aims to achieve the following objective:

To explore the essential factors that influencing the enhancement usage of mobile gamifiction applications.

The remainder of the research paper is organized as follows: Section 2 presents the theoretical background and the research model of this study. In the section 3, we explain the research method. Section 4 includes the research findings. Finally, sections 5 and 6 concludes with the discussions and conclusions.

\section{THEORETICAL BACKGROUND AND RESEARCH MODEL}

Mobile gamification is a useful digital tool for learning process using mobile games. This kind of games based learning now is one of the most important topics in modern education and is rapidly growing research trend [6], around the adoption of mobile games in the learning process and their impact on students' learning effectiveness. A review of mobile gamification literature by Koutromanos and Avraamidou [10], who commented on the need for further studies into how students use and accept mobile gamification applications in effectively way in higher education in order to enhance the sustainability of learning. Rashid, Salleh, and Noor [11] identified that the main challenge for the successful integration of mobile gamification into learning activities is relevant significantly to students' acceptance.

In order to solve this issue, several researchers have started to clarify the factors that affect students' usage and acceptance of educational mobile and digital games. For example, Dele-Ajayi et al. [21] used TAM to identify the factors that influence intention to continuously use digital educational games. Their results showed that the users' acceptance of digital games was positively influenced by perceived ease of use, perceived and self-efficacy. They also revealed that TAM model is a useful instrument for exploring the attitude of learners to accepting digital games for learning. Chen and Lin [22] also employed the TAM, aiming to examine Chinese students' acceptance of mobile games in the classroom. Their results suggested that the students' preference for using mobile games was most significantly affected by their perception of usefulness and ease of use. In another study, Wang and Sun [23] also applied TAM to examine students' acceptance of an educational computer game. Their findings showed that perceived ease of use and perceived usefulness significantly influenced students' acceptance of the proposed game. However, these studies not only signified the extensive use of TAM in examining students' acceptance of digital games, but also indicated the lack of scholarly attention to the critical role of some other important factors such as enjoyment, efficiency and effectiveness behind students' utilization of mobile games applications.

In fact, one of the main concerns in the literature of educational digital games adoption is assuring students utilization and of the mobile games [12]. Several studies have investigated the following question: what are the main factors affecting students' utilization of educational mobile games. Most of these works have focused on the TAM constructs to investigate the students' utilization of educational mobile games. After the introduction of TAM, educational mobile games studies have merely focused on use-based view of users acceptance [13]. In other word, researchers have used the main constructs of TAM such as ease of use and usefulness actual use and intention to use to study the utilization of educational mobile games.

According to previous studies, constructs of TAM model like perceived ease of use, perceived usefulness and behavioural intention to use have been widely used to evaluate users' utilization of several types of educational technologies [14],[15],[16]. Perceived usefulness means that "the degree to which a person believes that using a particular system would enhance his or her job performance", and perceived ease of use signifies "the degree to which a person believes that using a particular system would be free from effort", and behavioural intention to use defined as the degree to which a user is willing to use a particular technology [20]. Moreover, investigating these constructs behind users' utilization of technologies have been proven helpful in providing users with more acceptable educational technologies, and therefore have been widely regarded as vital factors for studying users' utilization of mobile technologies [17], [18],[19]. For example, Dele-Ajayi et al. [21] used TAM to identify the factors that influence intention to use digital educational games. Their results showed that the users' acceptance of digital games was positively influenced by perceived ease of use, perceived and self-efficacy. They also revealed that TAM model is a useful instrument for exploring the attitude of learners to accepting digital games for learning. Chen and Lin [22] also employed the TAM, aiming to examine Chinese students' acceptance of mobile games in the classroom. Their results suggested that the students' preference for using mobile games was most significantly affected by their perception of usefulness and ease of use. In another study, Wang and Sun [23] also applied TAM to examine students' acceptance of an educational computer game. Their findings showed that perceived ease of use and perceived usefulness significantly influenced students' acceptance of the proposed game. 
Based on this discussions, this study proposes the following hypotheses as shown in the research model in Figure 1:

H1: Perceived ease of use has a significant relationship with users' intention to use of mobile gamification.

H2: Perceived usefulness has a significant relationship with users' intention to use of mobile gamification.

H3: Perceived ease of use has a significant relationship with perceived usefulness of mobile gamification.

H7: Behavioural intention to use has a significant relationship with users' utilization of mobile gamification.

Furtheremore, current studies have indicated that perceived enjoyment is one of the crucial factors motivating students to use digital game applications [24],[25]. For example, a study conducted by Baek [24], who investigated the factors that influence individuals' acceptance of mobile learning games. They found that perceived enjoyment is the key factor that determines individuals' utilization of mobile learning game applications. Gökalp [25], also found that perceived enjoyment had a significant influence on students' behavioural intentions to use mobile games applications among students. Overall, these studies not signified the extensive use of perceived enjoyment in examining students' utilization of educational mobile games, also there is lack of scholarly attention to investigate the influence of perceived ease of use and perceived usefulness on perceived enjoyment in order to encourage students' utilization of mobile games applications. Based on that this research seeks to fill this research gap by investigating the following hypotheses:
H4: Perceived ease of use has a significant relationship with perceived enjoyment of mobile gamification.

H5: Perceived usefulness has a significant relationship with perceived enjoyment of mobile gamification.

H6: Perceived enjoyment has a significant relationship with users' intention to use of mobile gamification.

According to efficiency and effectiveness factors, some studies have found that both factors have significant and positive influence on users' utilization of technologies [26]. However, no one of current studies have examined the effect of efficiency and effectiveness on students' utilization of educational mobile game applications. Thereby, in the research model of this study, utilization of mobile gamification applications is measured by two main constructs are effectiveness and efficiency, as shown in Figure 1. Therefore, this study proposes the following:

H8: Perceived enjoyment has a significant relationship with effectiveness of mobile gamification.

H9: Perceived enjoyment has a significant relationship with efficiency of mobile gamification.

H10: Effectiveness has a significant relationship with users' utilization of mobile gamification. of mobile gamification.

H11: Efficiency has a significant relationship with users' utilization of mobile gamification. of mobile gamification.

\section{H5}

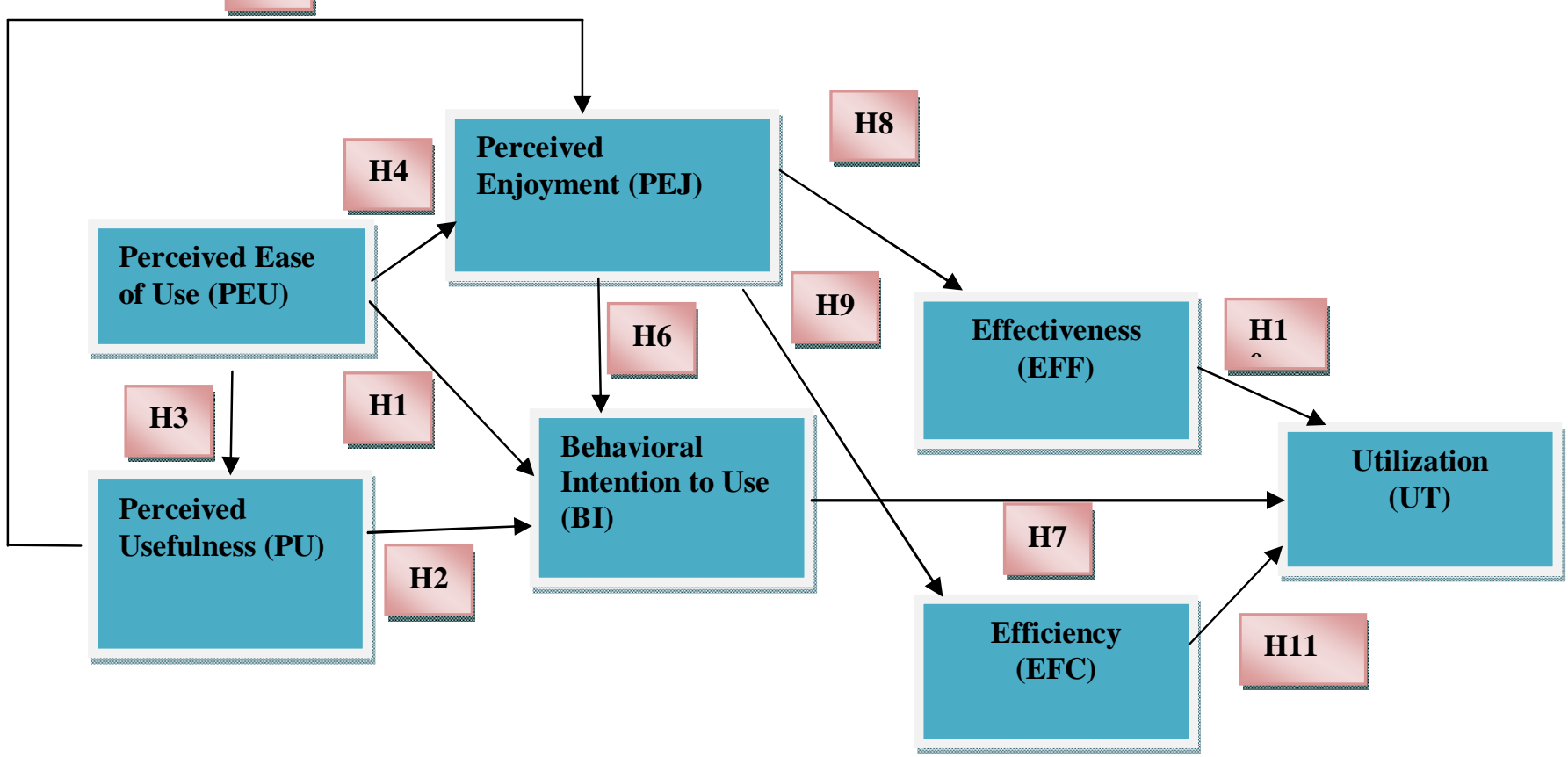

FIGURE 1. Research Model 


\section{RESEARCH METHOD}

\subsection{SAMPLE AND DATA COLLECTION}

In this research, an online questionnaire survey was employed for data collection due to the Covid-19 pandemic lockdown situation. The researchers of this study had distributed the online questionnaire via email and Google sheet for students at five universities in Saudi Arabia. These universities have already developed e-learning system and mobile learning system in their settings. Using online survey questionnaire, students were invited to participate in this study through online classes, during the summer semester 2020. The participants in this study were from different colleges.

Due to Covid-19 and its prevention face to face data collection was not possible. The questionnaire in the form of Google Sheet has been sent to the students through university lecturers. They were asked to fill the form and submit their responses if they were willing to participate in the research. The participants had not forced to participate in this research and it was clearly mentioned that if they didn't like to continue then they were not forced to submit the form. In total, 417 online questionnaires were distributed, with 399 questionnaires being returned, indicating an $95.68 \%$ response rate. Using guidelines by Sekaran [29], the target minimum sample size for the study was 384 participants. Therefore, the sample size in this research is acceptable. Most of responses had incomplete or invalid answers and therefore were excluded. Hence, 397 responses were considered valid for further analysis. Among 399 valid responses, $52.7 \%$ of respondents were female, while $47.3 \%$ were male. Moreover, $52.6 \%$ of respondents who responded were undergraduate; $47.4 \%$ were postgraduate students.

\subsection{INSTRUMENT ITEMS}

The items and scales for measuring the hypotheses in the proposed research model were derived from existing prior studies. The online questionnaire included two main parts, the first part included demographic information such as gender, age and others. The second part included the variables in the research model, including enjoyment, perceived ease of use, perceived usefulness, behavioural intention to use, efficiency, effectiveness and utilization. As presented in Table 1, the items for measuring enjoyment construct was adopted from a study of mobile learning games conducted by Baek and Touati [27]. The scales of perceived ease of use, perceived usefulness and behavioural intention to use were taken from technology acceptance model study by Davis [20]. The measurement items for efficiency, effectiveness and utilization constructs were developed from Ghapanch and Talaei-Khoei [26]. In our research, we used a 5 point scale similar to Likert scale for measuring all items, ranging from "strongly disagree $=1$ " to "strongly agree $=5$ ". We requested from seven experts in the field of digital games development, each of them holding Associate Professors and Professors rank and they have more ten years experience for testing the appropriateness and clarify of the questionnaire items before conducting the study. After that, we conducted a pilot study with 37 students from King Faisal University for testing the reliability and validity of the questionnaire items. The results indicated that questions and items were completely understood.

Table 1. Instrument items and their resources

\begin{tabular}{lcc} 
Factors & Number of items & Sources \\
\hline Perceived Enjoyment (PEJ) & 4 & Baek and Touati [27] \\
\hline Perceived Ease of Use (PEU) & 3 & Davis [20] \\
\hline Perceived Usefulness (PU) & 3 & Davis [20] \\
\hline Behavioral Intention to Use (BI) & 3 & Davis [20] \\
\hline Effectiveness (EFF) & 3 & Ghapanch and Talaei [26] \\
\hline Efficiency (EFC) & 3 & Ghapanch and Talaei [26] \\
\hline Utilization (UT) & 3 & Ghapanch and Talaei [26] \\
\hline
\end{tabular}

\subsection{BATA ANALYSIS METHODS}

In our research, we have employed two methods to analyze the data and evaluate the proposed hypotheses in the research model. The first method is the confirmatory factor analysis (CFA) in order to evaluate the measurement model in terms of reliability, convergent validity, and discriminant validity. In the second technique, a structural equation modelling (SEM) method was applied to test the proposed relationships in the research model.

\section{RESEARCH FINDINGS}

\subsection{RELIABILITY ANALYSIS FINDINGS}

The Cronbach's alpha analysis was employed to evaluate the reliability of items for each construct in the proposed research model. As the results summarized in Table 2, the 
value of this coefficient ranged between 0.796 and 0.917 , exceeding the critical value of 0.7 as suggested by Kannan and Tan [30], and indicating satisfactory reliability for all variables in the proposed research model.

Table 2. Findings of Cronbach's Alpha and AVE

\begin{tabular}{lcc}
\hline Factors & Cronbach's alpha & $\begin{array}{c}\text { Average Variance Extracted } \\
\text { (AVE>0.5) }\end{array}$ \\
\hline Perceived Enjoyment (PEJ) & 0.887 & 0.796 \\
\hline Perceived Ease of Use (PEU) & 0.865 & 0.801 \\
\hline Perceived Usefulness (PU) & 0.917 & 0.862 \\
\hline Behavioral Intention to Use (BI) & 0.902 & 0.847 \\
\hline Effectiveness (EFF) & 0.853 & 0.826 \\
\hline Efficiency (EFC) & 0.796 & 0.752 \\
\hline Utilization (UT) & 0.887 & 0.840 \\
\hline
\end{tabular}

\subsection{CONVERGENT AND DISCRIMINANT ANALYSIS FINDINGS}

In this study, all variables in the proposed model were evaluated using two types of validity analysis: convergent and discriminant validity. For convergent validity analysis, Table 2 shows that the average variance extracted (AVE) was above (0.5). According to Hair et al. [31], specify that a variance greater than 0.5 is acceptable. Therefore, the convergent validity values for the research constructs are acceptable. Concerning the discriminant validity analysis, the square root of AVE was obtained to correlate the latent constructs. Table 3 highlights that the square root of the AVE for each construct is greater than the pairwise correlations. This result means that the psychometric characteristics of the instrument are also deemed acceptable in terms of their discriminant validity [32].

Table 3. Findings of Discriminant Validity Analysis

\begin{tabular}{lccccccc}
\hline & PEJ & PEU & PU & BI & EFF & EFC & UT \\
\hline PEJ & $\mathbf{0 . 9 0 7}$ & & & & & & \\
PEU & 0.797 & $\mathbf{0 9 4 1}$ & & & & & \\
PU & 0.630 & 0.758 & $\mathbf{0 . 9 5 3}$ & & & & \\
BI & 0.646 & 0.684 & 0.545 & $\mathbf{0 9 5 9}$ & & & \\
EFF & 0.759 & 0.769 & 0.563 & 0.689 & $\mathbf{0 9 4 4}$ & & \\
EFC & 0.769 & 0.792 & 0.643 & 0.707 & 0.790 & $\mathbf{0 9 8 2}$ & \\
UT & 0.530 & 0.623 & 0.506 & 0.643 & 0.527 & 0.614 & $\mathbf{0 9 8 5}$ \\
\hline
\end{tabular}

\subsection{STRUCTURAL MODEL ANALYSIS FINDINGS}

The results of the structural model analysis indicated that 11 hypotheses were supported, as presented in Table 4 . The findings indicated that that perceived ease of use have a significant and positive influence on perceived enjoyment $(\beta$ -value $=0.362, p<0.001)$, perceived usefulness $(\beta$-value $=$ $0.475, \mathrm{p}<0.001)$ and behavioural intention to use $(\beta$-value $=$ $0.325, \mathrm{p}<0.001)$, these results supporting hypotheses $\mathrm{H} 1$, $\mathrm{H} 3$ and H4. The findings also found that perceived usefulness have a significant and positive influence on students' perceived enjoyment $(\beta$-value $=0.417, \mathrm{p}<0.001)$ and their behavioural intention to use $(\beta$-value $=0.392, \mathrm{p}<$ $0.001)$. Thus, the hypotheses $\mathrm{H} 2$ and $\mathrm{H} 5$ were supported. In addition, the results supported H6 ( $\beta$-value $=0,542$, p < 0.001 ), which indicated that perceived enjoyment have a significant and positive influence on students' behavioural intentions to use. Furthermore, the findings revealed that perceived enjoyment have a significant influence on perceived effectiveness $(\beta$-value $=0,496, \mathrm{p}<0.001)$ and perceived efficiency $(\beta$-value $=0,479, \mathrm{p}<0.001)$, this means that hypotheses $\mathrm{H} 8$ and $\mathrm{H} 9$ were supported. Finally, the findings confirmed that utilization influenced significantly and positively by behavioural intention to use $(\beta$-value $=0.527, p<0.001)$, perceived effectiveness $(\beta$ -value $=0,317, \mathrm{p}<0.001)$ and perceived efficiency $(\beta$-value $=0,242, \mathrm{p}<0.001)$, thus, H7, H10 and H11 were supported. 
Table 4. Findings of SME Analysis

\begin{tabular}{llll}
\hline Hypotheses & $(\beta)$ value & T-value & Results \\
\hline H1: PEU $\rightarrow$ BI & $0.325^{* *}$ & 2.994 & Supported \\
\hline H2: PU $\rightarrow$ BI & $0.392^{* *}$ & 3.837 & Supported \\
\hline H3: PEU $\rightarrow$ PU & $0.475^{* * *}$ & 9.015 & Supported \\
\hline H4: PEU $\rightarrow$ PEJ & $0.362^{* *}$ & 4.023 & Supported \\
\hline H5: PU $\rightarrow$ PEJ & $0.417^{* * *}$ & 5.017 & Supported \\
\hline H6: PE $\rightarrow$ BI & $0.542^{* * *}$ & 6.042 & Supported \\
\hline H7: BI $\rightarrow$ UT & $0.527^{* * *}$ & 5.098 & Supported \\
\hline H8: PEJ $\rightarrow$ EFF & $0.496^{* * *}$ & 5.357 & Supported \\
\hline H9: PEJ $\rightarrow$ EFC & $0.479^{* * *}$ & 5.045 & Supported \\
\hline H10: EFF $\rightarrow$ UT & $0.317^{* *}$ & 2.875 & Supported \\
\hline H11: EFC $\rightarrow$ UT & $0.242^{* *}$ & 2.435 & Supported \\
\hline
\end{tabular}

\section{DISCUSSIONS}

According to the literature, understanding the effective factors that could enhance students' utilization of educational mobile games has considered as a crucial step to success these applications. However, investigating these factors has received little scholarly attention. Therefore, in order to fill this gap, this study developed a conceptual model to understand the effective factors for enhancing students' utilization of educational mobile games. To attain the research objective, an empirical design with a research model was developed to investigate the role of six important factors, perceived enjoyment, perceived ease of use, perceived usefulness, behavioural intention to use, efficiency and effectiveness on students' utilization of educational mobile games. The research results indicated that the introduction of these important factors in the development process of mobile game applications had a significant and positive effect on enhancing utilization of mobile gamification applications among students, and thus, will increase the sustainability of learning effectively using mobile game applications.

Table 5 presents the empirical analysis results of the hypothesized relationships between the constructs in the proposed research model in Figure 1. The findings indicated that perceived ease of use had a direct significant and positive influence on perceived enjoyment, perceived usefulness and behavioural intention to use. This implies that the perceived ease of use have a significant and positive effect on students' utilization of educational mobile games significantly. The logical explanation of these results because when the mobile game applications more easier to play, use and learn and thereby exerts a positive effect on students' perceived usefulness of the game, enjoyment in playing the game, and thus enhancing their behavioural intention to use the educational mobile game applications. In contrast, when students face difficult games due to the lack of ease of use, this will make them to give up playing the game to learn. Moreover, ease of use factor plays an a key role in increasing the students enjoyment through helping them to tackle the challenges in the stages mobile games more easily through using some facilitations such as tips and guidelines to accomplish the mission, this will promote students motivation to learn by mobile gamification applications, and thus, will increase the sustainability of learning. These results are consistent with a study conducted by Huang [27] to study the main factors that could affect on students' utilization of computer games. The study found that perceived ease of use had a significant and positive influence on students' behavioural intention, which might be explained that students interest in learning by games has been increased when they find these games are easy to use, easy to play and easy to learn. Also, it might be explained that students perceive that the learning by mobile game applications more easily as compared to computer games.

The findings of this study also showed that perceived usefulness had a significant and positive influence on students' perceived enjoyment and their behavioural intention to use. This means that the perceived usefulness have a significant and positive effect on students' utilization of educational mobile games significantly. These results can be explained through that when students feel that mobile game applications will helps them to easily understand the learning materials content in a fun way, this will enhance their learning effectiveness and performance, and thus, will increase students' motivation to play it. These results are inconsistent with Huang [27] who found that students' perceived usefulness had no significant and positive influence on their behavioural intention, which might be explained that students perceive that the learning by mobile game applications more useful and fun than computer games due to unique characteristics of Smartphones. Also, it might be explained by their lack of interest in learning by computer games that led to their ignorance of the usefulness of the games.

The results revealed that perceived enjoyment had a significant and positive influence on students' behavioural intentions to use mobile game applications. The results showed that perceived enjoyment was the most important factor in enhancing students' utilizations of mobile game applications. The main explanation for this result is that students preferred the use of mobile game applications in their learning because these applications were as entertainment tool that brought them fun and pleasure; and thus, served as the key factor that influenced their intention to use the mobile 
game applications. This result is agreement with a study findings of Baek and Touati [28], they found that perceived enjoyment is the key factor that determines individuals' utilization of mobile learning games.

In terms of the relationship between perceived enjoyment with perceived effectiveness and perceived efficiency, the findings revealed that perceived enjoyment had significant influence on perceived effectiveness and perceived efficiency of mobile game applications. This explains that students in this study were interested in the entertainment as an helping tool for learning, and thus perceived enjoyment is a significant factor behind enhancing students' learning effectiveness and efficiency. In addition, this factor played a significant role in their utilization of the mobile game applications. In other words, students prefer the mobile game applications as entertainment tool for enhancing their learning effectiveness and efficiency and they perceive that the usefulness of the mobile game applications for their learning process could be achieved through providing enjoyment for them through playing. This result inconsistent with a study conducted by Huang [27], who found that perceived enjoyment is not a significant factor behind enhancing students' learning effectiveness and efficiency. It might be explained this result that students did not care about the usefulness of the educational mobile game as a tool for enhancing their learning effectiveness and efficiency; they preferred the educational mobile games as entertainment tool.

Furthermore, the results revealed that effectiveness and efficiency had a significant and positive influence on students' utilization of mobile game applications. This implies that effectiveness and efficiency have a significant and positive effect on students' utilization of educational mobile games significantly. The logical explanation of these results because the unique features of mobile devices and applications increased students' interest for learning through the mobile games more than as an entertainment tool. This finding is consistent Hwang et al. [29], who mentioned that the introduction of learning strategies in educational computer games might not only improve students' learning effectiveness but also reinforce their learning efficiency. Finally, the findings indicated that the developed model in this research is able to explain $67.7 \%$ of the variance in students' utilization of mobile game applications. The results of this research present several recommendations to help developers and designers of mobile games to promote students' utilization of mobile game applications.

\section{CONCLUSIONS}

This research aimed to investigate the sustainability of mobile gamification applications by proposing a conceptual model to explore the essential factors that influence on students' utilization of mobile game applications. The findings of this study present an valuable theoretical and practical recommendations for researchers, practitioners and developers about the critical factors for enhancing the utilization of mobile game applications, which can be summarized as following: first, perceived ease of use had a direct significant and positive influence on perceived enjoyment, perceived usefulness and behavioural intention to use. This implies that the perceived ease of use have a significant and positive effect on students' utilization of educational mobile games significantly. Second, perceived usefulness had a significant and positive influence on students' perceived enjoyment and their behavioural intention to use. This means that the perceived usefulness have a significant and positive effect on students' utilization of educational mobile games significantly. Third, perceived enjoyment had a significant and positive influence on students' behavioural intentions to use mobile game applications. The results showed that perceived enjoyment was the most important factor in enhancing students' utilizations of mobile game applications. Fourth, perceived enjoyment had significant influence on perceived effectiveness and perceived efficiency of mobile game applications. This explains that students in this study were interested in the entertainment as an helping tool for learning, and thus perceived enjoyment is a significant factor behind enhancing students' learning effectiveness and efficiency. Finally, effectiveness and efficiency had a significant and positive influence on students' utilization of mobile game applications. The results of this research present several recommendations to help developers and designers of mobile games to promote students' utilization of mobile game applications, and thus, enhancing the sustainability of learning using mobile game applications.

\section{ACKNOWLEDGMENT}

The authors extend their appreciation to the Deputyship for Research \& Innovation, Ministry of Education in Saudi Arabia for funding this research work through the project number IFT20020.

\section{REFERENCES}

[1] Pechenkina, E., Laurence, D., Oates, G., Eldridge, D., \& Hunter, D. (2017). Using a gamified mobile app to increase student engagement, retention and academic achievement. International Journal of Educational Technology in Higher Education, 14(1), 1-12.

[2] Bicen, H., \& Kocakoyun, S. (2017). Determination of University Students' Most Preferred Mobile Application for Gamification. World Journal on Educational Technology: Current Issues, 9(1), 18-23.

[3] Rachels, J. R., \& Rockinson-Szapkiw, A. J. (2018). The effects of a mobile gamification app on elementary students' Spanish achievement and self-efficacy. Computer Assisted Language Learning, 31(1-2), 72-89.

[4] Wiggins, B. E. (2016). An overview and study on the use of games, simulations, and gamification in higher education. International Journal of Game-Based Learning (IJGBL), 6(1), 18-29.

[5] Varannai, I., Sasvári, P. L., \& Urbanovics, A. (2017). The use of gamification in higher education: an empirical study. International Journal of Advanced Computer Science and Applications, 8(10), 1-6. 
[6] Villanueva, K., \& Vaidya, J. (2019). Power up Learning With Mobile Games: The Educational Arcade-An Innovative Approach to Learning. In Advancing Mobile Learning in Contemporary Educational Spaces (pp. 209-242). IGI Global.

[7] Holden, C. L., \& Sykes, J. M. (2011). Leveraging mobile games for place-based language learning. International Journal of Game-Based Learning (IJGBL), 1(2), 1-18.

[8] Huizenga, J., Admiraal, W., Akkerman, S., \& Dam, G. T. (2009). Mobile game $\square$ based learning in secondary education: engagement, motivation and learning in a mobile city game. Journal of Computer Assisted Learning, 25(4), 332-344.

[9] Prensky, M. (2001). Digital natives, digital immigrants. On the horizon, 9(5).

[10] Dreimane, S. (2019). Gamification for education: Review of current publications. In Didactics of smart pedagogy (pp. 453-464). Springer, Cham.

[11] Rashid, N. A. M., Salleh, S. M., \& Noor, N. M. (2018). The Role of Game Elements in Improving Jawi Skills through a Mobile Game'G-Jawi'. International Journal of Interactive Mobile Technologies (iJIM), 12(7), 20-30.

[12] Mivehchi, L., \& Rajabion, L. (2020). A framework for evaluating the impact of mobile games, technological innovation and collaborative learning on students' motivation. Human Systems Management, 39(1), 27-36.

[13] Ghani, M. T. A., Hamzah, M., Ramli, S., Ab, W., Daud, A. W., Romli, T. R. M., \& Mokhtar, N. N. M. (2019). A Questionnaire-Based Approach on Technology Acceptance Model for Mobile Digital Game-Based Learning. Journal of Global Business and Social Entrepreneurship (GBSE), 5(14).

[14] Almaiah, M. A., Jalil, M. A., \& Man, M. (2016). Extending the TAM to examine the effects of quality features on mobile learning acceptance. Journal of Computers in Education, 3(4), 453-485.

[15] Almaiah, M. A., \& Alismaiel, O. A. (2019). Examination of factors influencing the use of mobile learning system: An empirical study. Education and Information Technologies, 24(1), 885-909.

[16] Almaiah, M. A., \& Man, M. (2016). Empirical investigation to explore factors that achieve high quality of mobile learning system based on students' perspectives. Engineering science and technology, an international journal, 19(3), 1314-1320.

[17] Almaiah, M. A. (2018). Acceptance and usage of a mobile information system services in University of Jordan. Education and Information Technologies, 23(5), 1873-1895.

[18] Almaiah, M. A., \& Al Mulhem, A. (2019). Analysis of the essential factors affecting of intention to use of mobile learning applications: A comparison between universities adopters and non-adopters. Education and Information Technologies, 24(2), 1433-1468.

[19] Almaiah, M. A., Alamri, M. M., \& Al-Rahmi, W. M. (2019). Analysis the effect of different factors on the development of Mobile learning applications at different stages of usage. IEEE Access, 8, 16139-16154.
[20] Davis, F. D. (1989). Perceived usefulness, perceived ease of use, and user acceptance of information technology. MIS quarterly, 319-340.

[21] Dele-Ajayi, O., Strachan, R., Sanderson, J., \& Pickard, A. (2017, April). A modified TAM for predicting acceptance of digital educational games by teachers. In 2017 IEEE Global Engineering Education Conference (EDUCON) (pp. 961-968). IEEE.

[22] Chen, H. R., \& Lin, Y. S. (2016). An examination of digital game-based situated learning applied to Chinese language poetry education. Technology, Pedagogy and Education, 25(2), 171-186.

[23] Wang, Q., \& Sun, X. (2016). Investigating gameplay intention of the elderly using an Extended Technology Acceptance Model (ETAM). Technological Forecasting and Social Change, 107, 59-68.

[24] Baek Y, Touati A. Exploring how individual traits influence enjoyment in a mobile learning game. Computers in Human Behavior. 2017 Apr 1;69:347-57.

[25] Gökalp, E. (2014, September). Determinants of Acceptance of Mobile Games through Structural equation Modeling. In MCIS (p. 11).

[26] Ghapanchi, A. H., \& Talaei-Khoei, A. (2018). Rethinking Technology Acceptance: Towards a Theory of Technology Utilization.

[27] Huang, Y. M. (2019). Exploring students' acceptance of educational computer games from the perspective of learning strategy. Australasian Journal of Educational Technology, 35(3).

[28] Baek, Y., \& Touati, A. (2017). Exploring how individual traits influence enjoyment in a mobile learning game. Computers in Human Behavior, 69, 347-357.

[29] Sekaran, Uma. "Research methods for business 4th edition. Hoboken." (2009).

[30] [47] V. R. Kannan and K. C. Tan, "Just in time, total quality management, and supply chain management: Understanding their linkages and impact on business performance," Omega, vol. 33, no. 2, pp. 153-162, 2005.

[31] J. F. Hair, J. W. Black, B. J. Babin, and R. E. Anderson, Multivariate data analysis, 7th ed. Englewood Cliffs, NJ, USA: Prentice-Hall, 2010.

[32] C. Fornell and D. F. Larcker, "Evaluating structural equation models with unobservable variables and measurement error", J. Marketing Res., vol. 18, no. 1, pp. 39-50, 1981.

[33] Alamri, M. M., Almaiah, M. A., \& Al-Rahmi, W. M. (2020). Social Media Applications Affecting Students' Academic Performance: A Model Developed for Sustainability in Higher Education. Sustainability, 12(16), 6471.

[34] Almaiah, M. A., \& Jalil, M. A. (2014). Investigating students' perceptions on mobile learning services. International Journal of Interactive Mobile Technologies (iJIM), 8(4), 31-36.

[35] Almaiah MA, Almulhem A. A conceptual framework for determining the success factors of e-learning system implementation using Delphi technique. Journal of Theoretical and Applied Information Technology. 2018 Sep $15 ; 96(17)$. 
[36] Almaiah, M. A., Alamri, M. M., \& Al-Rahmi, W. (2019). Applying the UTAUT Model to Explain the Students' Acceptance of Mobile Learning System in Higher Education. IEEE Access, 7, 174673-174686.

[37] Almaiah, M. A., \& Alyoussef, I. Y. (2019). Analysis of the Effect of Course Design, Course Content Support, Course Assessment and Instructor Characteristics on the Actual Use of E-Learning System. IEEE Access, 7, 171907-171922.

[38] Almaiah, M. A., \& Al-Khasawneh, A. Investigating the main determinants of mobile cloud computing adoption in university campus. Education and Information Technologies, 1-21.

[39] Shawai YG, Almaiah MA. Malay language mobile learning system (MLMLS) using NFC technology. International Journal of Education and Management Engineering. 2018 Mar 1;8(2):1.

[40] Almaiah MA, Nasereddin Y. Factors influencing the adoption of e-government services among Jordanian citizens. Electronic Government, An International Journal. 2020;16(3):236-59.

[41] Almaiah MA, Al-Khasawneh A, Althunibat A. Exploring the critical challenges and factors influencing the E-learning system usage during COVID-19 pandemic. Education and Information Technologies. 2020 May 24:1.

[42] Alamri MM, Almaiah MA, Al-Rahmi WM. The Role of Compatibility and Task-Technology Fit (TTF): On Social Networking Applications (SNAs) Usage as Sustainability in Higher Education. IEEE Access. 2020 Sep 4;8:161668-81.

[43] Almaiah, M., Al-Khasawneh, A., Althunibat, A., \& Khawatreh, S. (2020). Mobile Government Adoption Model Based on Combining GAM and UTAUT to Explain Factors According to Adoption of Mobile Government Services.

[44] Almaiah, M. A., \& Alamri, M. M. (2018). Proposing a new technical quality requirements for mobile learning applications. Journal of Theoretical and Applied Information Technology, 96, 19. 